\title{
The Art of Leadership: Educational and Business Leaders Speak Out On Organizational Change
}

\author{
Marsha L. Carr \\ University of North Carolina at Wilmington
}

\begin{abstract}
Leadership is a common ground. The skills to run a corporation are akin to the skills needed to oversee and operate a school system. The identification of the similar skills provides opportunity for business and educational leaders to work together on common challenges. This study identifies the similar leadership skills necessary to lead two different organizations. A qualitative study was designed to identify these characteristics in both business and educational leadership for a comparative analysis.
\end{abstract}

\section{Introduction}

While leadership is discussed as a common ground, books are written to provide guidance to educational leaders suggesting there are more differences than similarities in educational leadership in comparison to business leadership. This study sets out to explore the common ground shared by business and educational leaders for the identification of leadership characteristics. Some questions that will be answered are, "What are the characteristics shared by business and educational leaders?" "How are these skills used by both leaders in two different systems?" "What are the similarities in these leadership settings that require similar skills?" "What are the differences in these leadership settings that require different skills?”

\section{Leadership}

Leadership varies in business and educational settings. Different types of leadership are used by educational and business leaders depending on the necessity of the situation. There are distinct levels of leadership and leadership support in various settings that differ between an educational and business environment. Educational leaders are more apt to be confronted, follow different types of leadership styles and more often encounter poor leadership than business leaders.

\section{Bureaucracy}

School systems are structured as a bureaucracy, but there are factors that are unique to this type of organization [2]. A bureaucracy, as defined in this study, refers to the routine process of administration that emphasizes precision, speed, clarity, regularity, reliability, and efficiency achieved through the creation of a "fixed division of tasks, hierarchical supervision, and detailed rules and regulations" (Morgan [24], p. 17). Henry Mintzberg (as cited in Morgan [24]), identified five types of bureaucracies: (1) machine, (2) divisionalized, (3) professional, (4) simple structure, and (5) adhocracy.

Schools are professional bureaucracies by design and are characterized by flat and tall hierarchies. In school systems, there are a fixed division of tasks created in departments or classes, evaluations are completed by supervisors in a hierarchical command, and the federal and state government provides detailed rules and regulations for personnel, finance, and other policies that govern the day-to-day operations of the organization. Businesses are free from the constraints of a bureaucratic model.

For the most part, school systems are operated under dual leadership. This leadership is a merger of the superintendent and the board of education. In most school systems, boards of education have high levels of power and can, at any time and without reason or just cause, remove the superintendent from office. A superintendent can be evaluated and receive high marks only to find that the board of education has decided to not renew his or her contract. The non-renewal does not require any justification or explanation. Therefore, with such power, a board of education can punish a superintendent who refuses to perform the desires of the board, regardless of the ethics or legality of the request. It is not uncommon for superintendents to lose contract renewals because of political disagreements or power struggles with the board of education [30]. Furthermore, there is no recourse for superintendents.

There is no prerequisite of skill or educational degree required for holding a board position. In many states, the position is either a non-paid position or among the lowest paid political positions compared to similar political roles. This level of power combined with the inequity of the job, creates vast concern as a leadership issue. School board members range in drive from civic-minded members who want to better the system he or she represents to a scorned citizen with a personal vendetta towards an employee in the system or the system in entirety. Regardless, once in office, a member resides for 4 years and has opportunity to use 
the time for the good or detriment of the organization, depending on personal agenda [30]. It is no wonder that superintendent leaders feel the cards are stacked against them when it comes to operating a school system in comparison to a business.

The research on educational leadership and business leadership has similarities and differences. It becomes inherent to understand how educational leaders view leadership and how business views leadership.

\section{Organizational Change in Education}

Berman and McLaughlin [3] conducted a multipleyear study on educational change for the United States Department of Education. Their study concluded the following: (a) successful projects have difficulty sustaining change, (b) no class of educational treatments were found to consistently improve student outcomes, (c) successful projects were not disseminated easily, and (d) replication in new sites often failed or did not produce the same results [28]. Berman and McLaughlin identified a small number of cases in which reform initiatives were sustained in their studies. They found sustainability was evident when there was planning and groundwork for sustaining the change. Leadership's support was also critical in the continued success of these initiatives. Berman and McLaughlin further cited active leadership and professional development as components of sustainability. In agreement, Datnow and Stringfield [10], who conducted a set of longitudinal studies in which schools were provided reform initiatives, found that leadership instability and the politics that accompanied leadership positions were challenges to sustainability in some cases. In each of the studies, few schools if any were able to sustain initiatives, four years after the reform. One study found that only one of 13 schools had sustained the initiatives, four years after the initial reform. Fullan [15] agreed that the single most powerful factor in undermining conditions for success is turnover, whether administrative or staff. Fullan further suggested that there are three fundamental issues to remember when leaders desire success. The first of these three problems is the ability to legislate solutions when urgency is driving the change. The second is the fact that success in one environment might not resemble success in a different environment. As such, "Success is $25 \%$ having the right ideas and $75 \%$ establishing effective processes that themselves are no guarantee since each situation is unique” (Fullan, p. 90). The third factor is that implementation and sustainability are not just technical problems but passion and commitment problems as well.

Larry Lezotte and Kathleen McKee [21] viewed leadership as a mental model that involves two dimensions: a vision of how the school will be and a vision of how the school will achieve these goals. Systems theory views school districts as separate components that must work together as a whole to achieve success. In this model, the commitment and vision of a team is used to build a foundation upon which to promote sustained success. A process must be developed by which demands on schools are prioritized to meet the goals as developed and committed by the team and technology is an important tool for monitoring and adjusting instruction to assess student achievement on a daily basis, if necessary. Data gathering, data analysis, and data display are valuable tools for providing feedback for making local decisions that impact the success of each school

Lezotte and McKee [21] maintain that public education: is a classic top-down bureaucracy, is deeply layered, has a strong cultural drive to resist change, strives to maintain the balance of status quo and does not embrace change (pp. 26-27). They also adhered to the idea that stakeholders anchor the system in place. Furthermore, Lezotte and McKee said that to create change in the system-in-place, the support of the stakeholder groups is essential.

Huberman and Miles [18] agreed with Lezotte and McKee [21] that institutionalization or embedding a belief in a system or society depends on several factors. The first factor was whether the initiative or change is embedded within the culture of the organization or system. The second factor depends on whether a set number of individuals within the systems are skilled in the delivery and committed to the change by the time of institutionalization. The final factor was whether there were established procedures to maintain or sustain the change.

\section{Organizational Change in Business}

Business leaders are also concerned with change. For businesses, change, as described by Lezotte and McKee, is a way of life inherent daily and almost hourly because the customers change as well as what they want, the products turnover with trends, and the economy is never stable. Businesses operate in what could be considered a state of positive flux.

Harvard Business School professor Nitin Nohria [25] conducted a study on the formula for sustained business success. Nohria studied 160 companies in 40 different industries over two 5-year periods to answer why some businesses flourish and others fail. Nohria developed a 4+2 formula for success [27]. Upon review of over 200 practices, Nohria found that there were primary and secondary practices that contributed to the sustained success of businesses. The $4+2$ formula premise portrayed the idea that companies will operate at optimal levels if they apply four primary practices (strategy, executive, culture, and organization) as well as two secondary practices (talent of employees, leadership and governance, innovation, or mergers and partnerships) [6]. Nohria theorized that if at least six of the eight practices are done (including all four of the primary practices and at least two of the four secondary practices), a business can sustain success; however, a business must do all six well. To fail at any one of the six is to fail collectively (Nohria, Joyce, \& Robertson, 
2003). Schlechty [30] agreed that sustained success in business and private corporations is limited, but the capacity to achieve sustained results is present in the management design. This design is not present in educational institutions. Schlechty would agree with the study by Nohria, Joyce, and Robertson showing educational institutions lack a management design accepting change as well as business models; therefore, change is difficult for school systems. He further explained that school systems and the districts that support these systems do not have the capabilities in place to sustain change. Private corporations that have these capabilities in place still encounter difficulty with change. If change is going to occur in school districts and their schools, then it will require those that lead to understand the complexity of change and the importance of introducing the capabilities necessary to nurture sustained change. Public education, at present, is destroying school districts and recreating them for short-term interest groups; this is political in nature and not in the best interest of creating a sustained environment of change. The justification for this hostile takeover is to ensure immediate success for the system; however, often these systems will covert back after the takeover or do not show any significant gain during the process. According to Schlechty, it is critical to reach sustained results in dissecting the components of a system in order to work toward sustained success and not short-term results as apparent in the takeover models used in public education. Not everyone is in agreement with Schlechty when it comes to takeover models of management or even public school management design. Are these just excuses for public education to not rise up and meet the goal at hand?

Collins [7] disagreed with the notion and believes that discovering what creates enduring or sustaining great organizations of any type should always be a focus. In simple terms, "Good is the enemy of great". Good schools have the ability to become great schools in the same way that good businesses can become great. Collins quickly pointed out that leadership cannot be the solution to everything; however, leaders can be instrumental in guiding a company from goodness to greatness through core beliefs and preserved values.

\section{Theoretical Framework}

While not constrained by a theory [9], this study used both critical theory [1]; Morrow \& Brown [23]; Simon \& Francis [31]) and systems theory [5] as interpretive and explanative frameworks. This study had simplified frameworks for developing a theoretical means of discovery (Huberman \& Miles [18]). These theories served as a background for building additional frameworks. Frame theory by Bolman \& Deal [4], culture theory (Schein [29]), and change theory of Lezotte \& Jacoby, [20]; Fullan [15]) were also considered for relevance and impact in the study. The placement of these theories was adjusted according to the information and feedback from the subjects during the study [9].

\section{The Study}

Seventeen superintendents and business leaders were selected and then interviewed in West Virginia and Pennsylvania to identify what mechanisms or characteristics sustained success in his/her respective systems during the months of December 2010 and January 2011. This qualitative study gathered data from superintendents presently working in the field. The leaders were located geographically throughout the state of West Virginia and Pennsylvania.

The leaders were chosen according to the success of each system or company in operation. In regard to the business leaders, the company success, as established through Franchise Awards and recognitions or other similar acknowledgements, was used as a selection tool. In regard to the superintendent leaders, the county school achievement, size, geographical location, and state ranking was reviewed and used to determine which superintendents would be participants. Not all superintendent leaders that met this criteria were available to be interviewed.

The interviews were held at various sites in the states for face-to-face meetings and when weather conditions in the mountain state prevented these meetings, and telephonic interviews were conducted using recording devices. A survey form was developed and used by both sets of participants. The study was not viewed as two separate groupings but merely a collection of leaders, some who worked in a bureaucratic model and others in a business model. The questions were designed to relate to both groups with little bias since the focus was primarily on how leadership characteristics are identified by leaders who operate systems successfully.

\section{The Participants}

Six female and eleven males leaders with almost 190 years of combined superintendent and business owner service were the participants in this study, and the educational leaders offered another 100 years of administrative experience outside of the superintendency such as directors, coordinators, assistant superintendents, principals, and assistant principals. The business leaders were owners or CEO's of the business in which they represented.

The educational participants represented a cross section of urban and rural schools as well as school size by enrollment. The business participants represented franchise and family owned business as well as business leaders who began operations from scratch. Ages of the superintendents and business leaders ranged from 45-50 through 65-70. While these factors were noted, they were not used in the data analysis from the interviews but were noted to ensure that the participants represented a cross section of leaders. The breakdown 
of the age range of the participants is representational in Figure 1:

\begin{tabular}{|l|l|l|l|l|l|l|}
\hline \multicolumn{7}{|l|}{ Age Range of Participants } \\
\hline Age & $\mathbf{4 5 -}$ & $\mathbf{5 0 -}$ & $\mathbf{5 5 -}$ & $\mathbf{6 0 -}$ & $\mathbf{6 5 -}$ & $\mathbf{7 0 -}$ \\
Range & $\mathbf{5 0}$ & $\mathbf{5 5}$ & $\mathbf{6 0}$ & $\mathbf{6 5}$ & $\mathbf{7 0}$ & $\mathbf{7 5}$ \\
\hline & 3 & 5 & 4 & 3 & 2 & 0 \\
\hline
\end{tabular}

Figure 1. Age Range of Participants

\section{Overview of Study}

The quintessential characteristic of this study was in striving towards a holistic understanding of leadership action regarding the interrelated activities engaged in by the subjects in a social situation. This characteristic, according to Feagin, Orum, and Sjoberg [13] was best suited by a case study approach. The goal of this study was not to merely describe experiences in the manner of a phenomenology study, but rather to explore a process. While at times a grounded theory design seemed appropriate to the study, in actuality, it was a process that was being studied as well as a leadership analysis component. The process was a two-stage procedure in gathering interviews from business leaders and superintendents.

There are multiple designs that could have accommodated qualitative data collection and analysis, so to narrow down this design field the researcher reviewed the research question (Fitzpatrick, Secrist, \& Wright, [14]) and determined that the study required an exploration of a procedure or process that occurred. This type of design was exploratory, and the occurrences detailed in this study are subject to interpretation [19], [8], all of which suggested a case study design. The most appropriate method to gather data to answer the research question was in-depth personal interviews with individuals in leadership roles who were directly involved in an organization. Because the data is qualitative, it was necessary to review qualitative research designs.

Approximately 20 questions were used with both groups of leaders. The questions were divided into two sections. The first section of questions was to gather information about the leader's environment such as, if it was a superintendent then enrollments, type of school, setting, and other related demographic information was obtained. If it were a business leader, then the type of business, age of business, history of the location and success, how the business was started or how long the business had been in practice, as well as any other pertinently valuable information. The second section of questioning more directly asked about leadership characteristics. Questions of this nature were, "Describe your leadership style"; "How does your style of leadership compliment your company"; "What are the most essential leadership skills for your work"; and
"What is the greatest challenge in leadership when creating a successful system.” The questions were not asked in any order but more of a random solicitation in a natural setting to gather information from each participant.

Once the interviews were completed, the results of the interviews were transcribed and used to sort in order to establish identifiable characteristics of sustainability that represented both the educational and business leaders. The results of the study are provided in the next section.

\section{Leadership Characteristics}

There was a distinct difference in how the educational leaders viewed leadership and organizational change in comparison to how the business leaders viewed leadership and organizational change when the characteristics were revealed. While this research work was designed as more of an exploratory study, hence, a relatively small sampling of business and educational leaders, additional research in this area would be inherently beneficial to the field of leadership as well as leadership.

Combined characteristics that defined the leadership and change for educational and business leaders were identified in six categories: (1) establishment of a shared process/procedure (vision), (2) placement of the right people in the right positions, (3) the removal of political infiltration or corruption, (4) a change in organizational culture, (5) a shift in power from one level to a multiple levels of authority, and (6) establishment of channels of communication inside and outside of the organization (Table 1).

Table 1. Leadership Change Characteristics

\begin{tabular}{|c|c|}
\hline Characteristics & Percentage \\
\hline $\begin{array}{c}\text { Shared Procedural } \\
\text { Process }\end{array}$ & $100 \%$ \\
\hline $\begin{array}{c}\text { Right People in } \\
\text { Right Place }\end{array}$ & $86 \%$ \\
\hline Politics & $86 \%$ \\
\hline Change in Culture & $86 \%$ \\
\hline Power shift & $43 \%$ \\
\hline $\begin{array}{c}\text { Channels of } \\
\text { Communication }\end{array}$ & $29 \%$ \\
\hline
\end{tabular}




\section{Leadership Characteristics}

The first characteristic remained the same for both types of organizations; the differences fell in the ordering of additional characteristics. Some characteristics, while labeled the same, had a different meaning for the business leaders than the educational leaders. The characteristics were identified for both the educational and business leaders and then ranked as provided in Table 2 and Table 3 for both organizational models.

Table 2. Ranking of Educational Leadership Characteristics

\begin{tabular}{|c|c|c|c|}
\hline Rank \% & $\begin{array}{c}\text { Rank } \\
\text { Order }\end{array}$ & Characteristic & Description \\
\hline $100 \%$ & 1 & Removal of Politics & $\begin{array}{c}\text { Removing political groups and agendas is a first and } \\
\text { foremost in public educational systems. }\end{array}$ \\
\hline $100 \%$ & 2 & Shared Procedural Process & $\begin{array}{c}\text { There must be a common focus or set of goals that is } \\
\text { embraced by all entities of the system. }\end{array}$ \\
\hline $86 \%$ & 3 & Shifting Power & Power must be distributed. \\
\hline $86 \%$ & 5 & Fit of People and Position & $\begin{array}{c}\text { The right people have to be aligned with the job/positions } \\
\text { and duties/responsibilities. }\end{array}$ \\
\hline $43 \%$ & 6 & Communication & $\begin{array}{c}\text { Communication should vertical and horizontal throughout } \\
\text { the system as well as promote two-way communications. }\end{array}$ \\
\hline
\end{tabular}

Table 3. Ranking of Business Leadership Characteristics

\begin{tabular}{|c|c|c|c|}
\hline Rank \% & $\begin{array}{c}\text { Rank } \\
\text { Order }\end{array}$ & Characteristic & Description \\
\hline $100 \%$ & 1 & Shared Procedural Process & $\begin{array}{c}\text { Continuously monitoring and stressing the focus of the } \\
\text { business daily through various means. }\end{array}$ \\
\hline $86 \%$ & 2 & Fit of People and Position & $\begin{array}{c}\text { Putting the best people in front of the customers and } \\
\text { providing incentive. }\end{array}$ \\
\hline $86 \%$ & 3 & Communication & $\begin{array}{c}\text { Communication is a process of constant repetitious training } \\
\text { almost daily for consistency with customers. }\end{array}$ \\
\hline $43 \%$ & 5 & Changing Culture & $\begin{array}{c}\text { Culture is that the customer is first and always first no matter } \\
\text { what. }\end{array}$ \\
\hline
\end{tabular}

In order to develop one list of characteristics of similar comparison, a weighted score was assigned to each of the characteristics by educational and business leaders. The scores were used to then rank order the combined skills for a collective skill list (Table 1).

A more detailed description and supporting evidence for each characteristic provides an overview for the category with testimony and explanation from the participant leaders. It will become apparent that leadership skills are similar and different for specific needs of each organization.

\section{Shared Procedural Process Characteristic}

One hundred percent of the subjects interviewed, business and educational leaders, agreed that process was a leadership characteristic. While this was second to political infiltration from the educational leaders, the business leaders shared that politics is not really a negative factor in what they do as a leader. Therefore, for all intent, with the exception of politics, the leaders both agreed that a shared procedural process was a first priority. 
For the purposes of this study, there are two components: the procedural aspect (training) and structural aspect of change (relationship building) that were revealed during the interviews. The leaders were also in agreement and believed that there were two subcharacteristics of process: training and relationships. Training was identified as an important component of the sustained success. Training was defined as content area staff development and specialized instruction in state code and policy for the educational leaders. Business leaders explained that training was constant and ongoing to sustain a successful system. Training was more about routine and everyday interaction. One business leader shared that he didn't actually describe it as training but technically his managers ...

"Were in training each and every day ... every second on the job. Every interaction I have with them is a form of training them and preparing them to be a better leader in my industry. Every question I have is a form of assessing their growth and every interaction is a means to improve their performance or educate them on the industry. That is my role as a leader. It is a form of either relationship building through training or training through relationship building, I don't know which comes first. They are so hand in hand and essential.” (Interview, 2011)

When it comes to relationships, a variety of relationships can evolve in a system. Morgan [24] recognized three types of relationships: unitary, pluralist, and radical. Furthermore, these authors stated that the relationship between individuals and society is parallel to the relationship between individuals and organizations. Unitary relationships underplay the role of power and use authority and control only to move the organization toward one common goal often through teamwork and empowerment. Pluralist relationships view power as a medium through which conflicts of interest are resolved and power holders have multiple sources of power. Radical relationships relate power as the key feature in the organization. In this type of relationship, power relations are built and model similar positions of power in society [24]. The leaders, in this study, expressed that unitary relationships are most common from the business perspective. Business leaders develop relationship with employees but equally are important the customers. Customers that feel they have a relationship with the business will return as repeat business. Relationships are key to the success of business leaders. Learning how to develop relationships among customers or having employees who can build relationships is important.

Educational leaders shared that unitary relationships are common, but unfortunately, due to board of education frequent use of radical relationships, superintendents are in less control to manage the type of relationships built in educational systems. Most of the educational leaders admitted to the frustration of being held accountable to business standards and lacking the empowerment to achieve the success in the same manner; therefore, superintendents have to be more strategic to navigate through the treacherous waters to have success. This, in turn, some leaders shared, is a credit of the fortitude and courage of a leader in the educational environment.

\section{Right People in Right Place Characteristic}

Business leaders were the first to stress the importance of having the right people in the right places within the system. One business leader described the process as

"I put my best players in front with the people [customer]. My customers deserve that. It would be unfair to my customers to place someone on the floor just because they met a prescribed set of qualifications based on certification. Often you don't know the value of an employee until they are placed in the specific role or environmental setting. I make my decisions based on what my customers need. I cannot imagine being forced to place a less than standard salesman on the floor. I could never be successful in my business. Why would I want to do that? Why would anyone want to make me do that? The focus is then on the employee and no longer the customer."

Educational leaders described frustrations with employment practices and identified problems with present hiring codes that do not allow administrators the flexibility to select what they referenced as the best 'fit' instead the candidates were selected on criteria established by state mandates that didn't always yield best placement of an individual. Emphasis in education is more on degrees, certifications, and points whereas business leaders were able to size up the needs of the organization and layer it with the right 'fit' of employees. Human resource is viewed as an indispensable component of the system. It makes or breaks the organization. Educational leaders place value on the human resource but not as strongly, according to the interviews, as the business leaders. One business leader, after school personnel hiring practices were explained, commented, "Those kinds of personnel policies would not be fair to my customers.” Many of the superintendent leaders agreed that it is not fair to the systems they serve or the students in the systems. Most indicated they did not see any changes coming forth in this area.

Collins [7] is a strong believer that anyone can succeed; it is a matter of wanting to change and only excuses prevent us from reaching these goals. So, are the educational challenges only excuses to keep from succeeding, or are they truly concrete blockage that needs to be respected for the challenge it represents? Good schools have the ability to become great schools in the same way that good businesses can become great, 
and while leadership cannot be the solution to everything, leaders can be instrumental in guiding a company from goodness to greatness through core beliefs and preserved values. Collins described five types, or levels, of leaders: level 1, highly capable individual; level 2, contributing team member; level 3 , competent manager; level 4, effective leader; and level 5 , executive. The first four are considered good leaders, but the level 5 leader is considered to be great. Collins described this type of leader as, "enduring greatness through a paradoxical blend of personal humility and professional will” (p. 20). Level 5 leaders desire the company to be more successful in the future than it is in the present. As such, these leaders are often present in great organizations. So, Collins advocates that it really isn't the system or the model, the successful sustainability of a system rests almost solely in the hands of the leader. While this has been disputed through some of the earlier studies in this paper, it may continue to be debatable for years to come.

\section{Political Characteristic}

Politics is a key factor only, from the perspective of the leaders interviewed, of educational systems. Business leaders admitted that political infiltration was neither a worry nor a hindrance in performing their duties as a leader. The businesses were really isolated from that and sheltered from that with exception to governmental regulations and policy, but even then, they shared it was not a concern that they had to deal with on a daily basis or even consider when making decisions for the betterment of the business.

For educational leaders, politics is a primary element in the environment they work daily and often hinders efforts for change in a system. Politics was defined by educational leaders as policy, state mandates, federal initiatives, and local political infiltration of governing boards. Politics, as a basic tenet of critical theory, plays a significant role in the educational system in two ways (Garland, 2003). Politics is defined as the competition between individuals or groups for power and leadership (Merriam-Webster Dictionary [22]). Garland believed that trouble schools are a result of territorial battles between political parties as well as can lead to or create a political atmosphere when local officials and activists enter. In these situations, "The politics of local control pits local politicians against politicians from state capitals, local education administrators against state education administrators, and state policy makers against local activists" (Garland, p. 11). Boards of education are a primary source of politics. The political dominance of special-interest groups in the election or appointment of a board member, as well as the daily operations of the board, handicaps boards from acting in the best interest of their position [30].

Sarason [28] offered a summary of one of the most detailed studies conducted on sustainability and politics in his book, Revisiting the Culture of the School and the
Problem of Change. According to Sarason, "introducing, sustaining, and assessing an educational change are political processes because they inevitably alter or threaten to alter existing power relationship, especially if that process implies, as it almost always does, a reallocation of resources” (p. 71). Any shift in leadership, such as a newly hired superintendent or a superintendent that actively follows the law, has the potential to threaten status quo by shifting or altering existing power relationships. Without preparation, this threat can create unanticipated consequences for a system. The superintendent leaders all had stories of interruptions to the system as well as what some referred to as battles with local political entities. These experiences are unique and applicable to school systems, whereas the business leaders are at least sheltered from this straight forward attack on a leader.

\section{Change in Culture Characteristic}

Culture refers to the attitude, customs, climate, and symbols recognized by a group of individuals in a particular environment. Insiders and outsiders are used to affect cultural change. Insiders (individuals that existed in the system prior to the takeover) are often employees and outsiders (individuals that are not part of the system) can provide a balance. For business, the focus is on the outsiders, those that evaluate the business every day. The internal individuals (employees) are responsible for the needs of the external individuals (customers). This relationship is critical to the success of the business. Educational systems are focused somewhat on external individuals but their primary focus is on internal individuals - the students (customers). Educational systems, often a victim of political maneuvering from the public, can be all but in battle with certain groups much to the distain of leadership, but lines are drawn and laws/policies have to be enforced. Superintendents do not see themselves as leaders when it comes to enforcement of codes and policy but merely managers of someone else's will and pleasure. This, from the perspective of the superintendents, is also a factor that un-levels the playing field when it comes to leadership. Superintendents have to navigate, again through treacherous waters, with outside political forces that fight for power over the system and manipulate board members to obtain control.

Culture is a process of reality construction. It is how people see and understand activities, events, actions, objects, language, and situations in the world with which they interact. This ability to make sense of these interactions and develop patterns for understanding is a basis for cultural development (Morgan [24]). In 1932, Willard Waller (as cited in Deal \& Kennedy [11]) wrote a perspective that is still relevant in 2004:

Schools have a culture that is definitely their own. There are, in the school, complex rituals of personal relationships, a set of folkways, mores, and irrational sanctions, a moral code 
based upon them. There are games, which are sublimated wars, teams, and an elaborate set of ceremonies concerning them. There are traditions, and traditionalists waging their world-old battle against innovators. (p. 69)

Culture, according to Deal and Kennedy [11], is each school's own unwritten rules and traditions, norms, and expectations, which are merely the way people act, the way people talk, the way people dress. These standards become embedded into the system and eventually become a culture. According to Deal and Peterson [12], culture can be either good or toxic and takeovers can remedy toxic cultures

The culture of an organization cannot be ignored nor neglected in significance to the overall success of the organization. Cultural baggage (characteristic of toxic organizations) is very difficult to remove. Deal and Peterson [12] suggested antidotes for cultural negativism. First, negativity should be confronted by giving people a chance to speak out. Second, positive cultures and staffs should be shielded and supported. Third, energy should be focused on recruiting, selecting, and maintaining a positive staff. Fourth, the positive should be celebrated. Finally, a conscious and direct focus should be placed on eradicating the negative while building on positive norms and beliefs. Culture, according to Deal and Peterson [12],

fosters school effectiveness and productivity; improves collegial and collaborative activities that foster better communication and problem-solving practices; fosters successful change and improvement efforts; builds commitment and identification of staff, students, and administrators; amplifies the energy, motivation, and vitality of a school staff, students, and community; and finally increases the focus of daily behavior and attention on what is important and valued. (p. 6-8)

Bolman and Deal [4] designed a framework to assist in understanding and framing cultures. There are four frames to understanding culture in frame theory: the structural frame, the human resource frame, the political frame, and the symbolic frame. The structural frame focuses on the goals, policies, and chain of command of the organization. The human resource frame identifies peoples' needs, skills, care, trust, and environment. The political frame deals with resources, power, conflict, negotiations, and compromise. The symbolic frame is about stories, rites, rituals, and symbols that represent the organization or system. Deal and Peterson [12] believed that some frames are more significant than others.

In the context of education, the structural frame is used heavily by policymakers to develop mandates for school systems. Day-to-day challenges faced by school officials are more often in the human resource frame. Schools, according to Sarason [28], are like many environments, a difficult system to measure due to the closed climate and attitude toward outsiders. Anyone outside of the educational system trying to infiltrate a school climate will undoubtedly be viewed as nefarious.

Schein [29] also provided three components of culture that assist organizations in understanding the importance of culture identification: artifacts, beliefs, and espoused values. The artifacts of an organization are its celebrated symbols or ceremonies. For many school systems, a winning football team or staterecognized debate team are the artifacts of the organization. Beliefs are the behaviors that are representative of the organization. For school systems, the belief that success is measured by achievement results is inherent. It is crucial to note that, "Modern organizations are sustained by belief systems that emphasize the importance of rationality, and their legitimacy in the public eye usually depends on their ability to demonstrate rationality and objectivity in action” (Morgan [24]). Espoused values are the deeplyingrained ethics and values that hold the organization together. Often this is what many recognize as the heartbeat of the organization (Schein [29]). The theory of change, according to Fullan [15], states,

To bring about more effective change, we need to be able to explain not only what causes it but how to influence those causes. To implement and sustain programs successfully, we need better implementation plans; to get better implementation plans, we need to know how to change our planning and follow-through process; to know how to change our planning process, we need to know how to produce better planners and implementers, and on and on. (pp. 93-94)

Fullan [15] identified four factors characteristic of change: need, clarity, complexity, and quality. First, there must be an identified need felt by those who will be impacted by the change. Thus, in a takeover, there should be an effort to identify who desires the change in the initialization stage. Second, there must be agreement in the change that is needed. This consensus should occur in the initialization stage. Third, those impacted by the change must understand the complexity in creating the change. During the implementation stage of a takeover, communication of how the change will occur and what is going to change is essential. Finally, there must be expectation on the quality of the change. It is the leadership that must drive the vision of the change and how the change will impact the system as a whole. Takeovers are viewed as an intrusion (Garland, 2003), and often, this advancement is unwelcome. In time, the advantages of intervention are seen by those impacted, but the change process was not the focus of this study, but rather how to sustain the results of positive change.

Power Shift Characteristic 
Shifting of power is considered a cultural change and Quinn [26] identifies this type of change as a structural change compared to a procedural. Power shifting between groups or individuals is common in both industry and educational environments; however, the way power is shifted appears to be different. In the business leaders' organizations, they expressed that leaders are to shift power to the salesman or employees in order to provide incentive. This is critical, as described by all business leaders. Educational leaders describe the power shifts as more from the superintendent to the board and back. These shifts are precipitated by the individuals that make up the board, community pressure or other external influence, as well as personality conflicts that arise. Sadly, most of the educational leaders expressed frustration that clients or students in this case are not really the consideration when the shifts occur and often the victim when it ends. One educational leader indicated, "as long as there are boards of education, you will have power shifts and struggles that cripple leaders from accomplishing goals.” The educational leaders expressed much more frustration in dealing with power shifts and seldom described them as a positive.

\section{Channels of Communication Characteristic}

Educational and business organizations are complex systems of reality built on relationships of power. Social positions and the interplay of historical contexts separate distinctive epistemological differences. Critical theory presupposes ontology of social reality that recognizes peculiar properties of social phenomena (Morrow \& Brown [23]). Since critical theory is entrenched in the philosophical notion that we create our own reality through our construction of our social environment, individuals and groups had differential control in constructing meanings. These meanings, as constructed, influenced the system. Groups also obtained power through the access of information. A focus on communication is eminent to understanding the relationships in an organization. All scientific knowledge is grounded in common sense and everyday life, and interpretative skills are grounded in experiences and prejudices or biases.

School systems have a structured flow that is inherent of a bureaucratic model; however, this is not necessarily akin to business models. The business leaders suggested that while they understood the need for such a hierarchy in education, this was not indicative of how communication flows in business. Communication is two-way between the manufacturer such as in the automobile industry or even motorcycle business, but there is also a strong flow of communication between the seller and the client. From the perspective of the business leaders, the most important communications occur between the seller and buyer. This flow of communication is what 'makes or breaks' the business. They describe the communication as more of a bottom up compared to top down in a bureaucratic model indicative of public education.

\section{Theoretical Findings}

True to the theoretical foundation of this study, a shared procedural process was a significant characteristic in both business and educational leadership and was the most common characteristic shared by the leaders. Both educational and business leaders were in agreement of the importance of providing training, staff development, and opportunity for those in the organization to be knowledgeable.

This study further suggested there is a relationship between leadership success and the people hired and placed within the organization that is essential to the success of the system. School systems spend approximately $85-90 \%$ of the budget on personnel in comparison to businesses that spent approximately 30\% on staff. Product was the primary budgetary expenditure for business. Notwithstanding budgetary allocations, both educational and business leaders viewed the hiring and placement of staff as a highly ranked characteristic in organizational change.

Politics was the single one factor that differed among the business and educational leaders during the identification of key characteristics. Political infiltration, as suggested by this study, unbalances the system and destroys the organization. It takes a considerable amount of time to undo damage created by the influx of political corruption. The central goal of critical theory is to create societies and workplaces free from domination and to provide equal opportunity in which public school systems may never be free of unwanted interference as long as board of education and outside influence is a component of the system. Business leaders have less hindrance or external influence to guard against.

Whether the system is a school or other agency, an organization should be balanced (Hunter \& Swann, [17]). When considering systems theory, the organization needs to be carefully balanced with a shared distribution of power that empowers others to carry out responsibility (Hatch [16]; Lezotte \& McKee, [21]).

\section{Conclusion}

In summary, this study is one perspective in the field of organizational change and leadership. While many companies and even school systems desire success and achieve it, sustaining this success for an extended period of time evades even the greatest of corporations and school systems. While states profess to insist on school improvement, it seems unlikely that even public school systems will yield the results desired by a nation demanding higher standards. Short-term success will not solve the problems facing school systems. Even hostile takeovers that continue to yield 
short-term success, will not offer a solution to solve the problems facing school systems. It is only through a relentless pursuit will answers be found to solve some of the problems facing educational and business leaders.

\section{References}

[1] Abercrombie, N., Hill, S., \& Turner, B. S. (1984). The penguin dictionary of sociology. New York: Penguin Books.

[2] Bass, B. M. (1990). Handbook of leadership: Theory, research and managerial applications (3rd ed.). New York: Free Press.

[3] Berman, P., \& McLaughlin, M. (1977). Federal programs supporting educational change: Factors affecting implementation and continuation. Santa Monica, CA: Rand Corporation.

[4] Bolman, L. G., \& Deal, T. E. (1997). Reframing organizations: Artistry, choice, and leadership. San Francisco: Jossey Bass Publishers.

[5] Capra, F. (1996). The web of life: A new scientific understanding of living systems. New York: Anchor Books.

[6] Cecil, M. (2003). To succeed, acquirers should vanquish targets, not play nice. Mergers \& Acquisitions Report, 16, 4.

[7] Collins, J. (2001). Why some companies make the leap and others don't: Good to great. New York: HarperCollins Publishers.

[8] Cone, J. D., \& Foster S. L. (2003). Dissertations and theses: From start to finish. Washington, DC: American Psychological Association.

[9] Creswell, J. W. (1994). Research Design: Qualitative and quantitative approaches. Thousand Oaks, CA: Sage Publications.

[10] Datnow, A., \& Springfield, S. (2000). Working together for reliable school reform. Journal of Educational for Students Placed at Risk, 5(1 \& 2), 183-204.

[11] Deal, T. E., \& Kennedy, A. A. (1982). Corporate cultures: The rites and rituals of corporate life. Reading, MA: Addison-Wesley.

[12] Deal, T. E., \& Peterson, K. D. (1999). Shaping school culture: The heart of leadership. San Francisco: Jossey Bass Publications.

[13] Feagin, J., Orum, A., \& Sjoberg, G. (Eds.). (1991). A case for case study. Chapel Hill, NC: University of North Carolina Press.

[14] Fitzpatrick, J., Secrist, J., \& Wright, D. J. (1998). Secrets for a successful dissertation. Thousand Oaks, CA: Sage Publications.

[15] Fullan, M. (2001). The new meaning of educational change. New York: Teachers College Press.

Garland, L. J. (2003). Navigating treacherous waters: A state takeover book. Lanham, MD: Scarecrow Press.
[16] Hatch, M. J. (1997). Organizational theory: Modern, symbolic, and postmodern perspectives. New York: Oxford University Press.

[17] Hunter, R. C., \& Swann J. (1999). School takeovers and enhanced answerability. Education and Urban Society, 31, 2.

[18] Huberman, M., \& Miles, M. (1984). Innovation up close. New York: Plenum.

[19] Leedy, P. D., \& Ormrod, J. E. (2001). Practical research: Planning and design. Upper Saddle River, N J: Merrill Prentice Hall.

[20] Lezotte, L. W., \& Jacoby, B. C. (1992). Sustainable school reform: The district context for school improvement. Okemos, MI: Effective Schools Products, Ltd.

[21] Lezotte, L. W., \& McKee, K. M. (2002). Assembly required: A continuous school improvement system. Okemos, MI: Effective Schools Products, Ltd.

[22] Merriam-Webster, (1997). The Merriam-Webster dictionary. Springfield, IL: Merriam-Webster, Inc.

[23] Morrow, R. A., \& Brown, D. D. (1994). Critical theory and methodology: Contemporary social theory. Thousand Oaks, CA: Sage Publications.

[24] Morgan, G. (1997). Images of organization. Thousand Oaks, CA: Sage Publishers.

[25] Nohria, N., Joyce, W., \& Robertson, B. (2003). What really works: The $4+2$ formula for sustained business success. New York: HarperCollins Publishers.

[26] Quinn, R. E. (1996). Deep change: Discovering the leader within. San Francisco: Jossey Bass Publishers.

[27] Raz, R. (2003). The 4+2 formula for success. Inc., 25, 42.

[28] Sarason, S. B. (1996). Revisiting the culture of the school and the problem of change. New York: Teachers College Press.

[29] Schein, E. H. (1992). Organizational culture and leadership. San Francisco: Jossey Bass Publications.

[30] Schlechty, P. C. (1997). Inventing better schools: An action plan for educational reform. San Francisco: Jossey Bass Publishers.

[31] Simon, M. K., \& Francis, J. B. (2001). The dissertation and research cookbook: A practical guide to help you start and complete your dissertation or research project. Dubuque, IA: Kendall Hunt Publishing Co. 